Original Articles

\title{
Reduction of Visceral Adiposity After Operation in a Subject with Insulinoma
}

\author{
Atsuhito Saiki ${ }^{1}$, Yoh Miyashita ${ }^{1}$, Kiyoji Wakabayasi ${ }^{2}$, Noriaki Kameda ${ }^{3}$, and Kohji Shirai ${ }^{4}$ \\ ${ }^{1}$ Center of Diabetes, Endocrine and Metabolism, \\ ${ }^{2}$ Department of Surgery, \\ ${ }^{3}$ Department of Pathology, \\ ${ }^{4}$ Department of Internal Medicine, Sakura Hospital, School of Medicine Toho University, Chiba, Japan.
}

\begin{abstract}
Generally, it is considered that visceral fat brings insulin resistance and hyperinsulinemia, in the mechanisms of metabolic syndromes. However, whether hyperinsulinemia brings about accumulation of visceral fat is not clear. We followed a case of insulinoma that caused primary hyperinsulinemia, and measured the change in visceral fat and insulin resistance before and after surgical resection of the insulinoma. A 58-year-old woman was admitted to investigate the cause of spontaneous hypoglycemia. An oral glucose tolerance test (OGTT) showed hyperinsulinemia with a high basal level and a glucagon infusion test showed an abnormally high insulin level. Abdominal computed tomography (CT) scan showed an accumulation of visceral fat. Selective celiac angiography showed a pancreatic tumor shadow. Under a diagnosis of insulinoma, the pancreatic body and tail were removed. At 3 months after the operation, the visceral fat area had decreased from 132.6 to $64.2 \mathrm{~cm}^{2}$. The fasting serum total cholesterol and triglyceride were also reduced. In addition, high-density lipoprotein cholesterol and preheparin serum lipoprotein lipase mass had increased. The midband on the polyacrylamide gel disc electrophoresis of lipoproteins, which appeared before operation, had disappeared completely. An OGTT showed a nondiabetic pattern after the operation. These results suggest that hyperinsulinemia might be one of the factors that enhance visceral adiposity and insulin resistance. $J$ Atheroscler Thromb, 2004; 11: 209-214.
\end{abstract}

Key words: Insulinoma, Metabolic syndrome, Visceral adiposity, Insulin resistance

\section{Introduction}

The co-existence of several metabolic abnormalities, including atherogenic dyslipidemia, hypertension, insulin resistance, obesity and a pro-thrombotic state, has been described as "visceral fat syndrome", "syndrome X", "insulin resistance syndrome", "the deadly quartet" and/or "the metabolic syndrome" (1-5). Visceral adipos-

Address for correspondence: Kohji Shirai, Department of Internal Medicine, Sakura Hospital, School of Medicine Toho University, 564-1, Shimoshizu, Sakura-city, Chiba 285-0841, Japan.

E-mail: kshirai@kb3.so-net.ne.jp

Received January 23, 2004.

Accepted for publication March 23, 2004. ity seems to play an important role in this syndrome. Generally, the causative mechanism of this syndrome is considered to be that visceral fat accumulation brings insulin resistance, accompanied by hyperinsulinemia. However, whether hyperinsulinemia brings about accumulation of visceral fat is not clear.

Insulinoma is a relatively rare endocrine tumor and causes primary hyperinsulinemia. There are some reports that insulinoma causes insulin resistance $(6,7)$, but the mechanism is not fully elucidated.

We report a case of insulinoma, and the change in visceral fat and insulin resistance before and after the operation. 


\section{Case Report}

A 58-year-old woman without diabetes mellitus or obesity complained of a 3-month history of dizziness at fasting. She had gained about $8 \mathrm{~kg}$ during the 3 months without overeating. She had no family history of endocrinopathy or diabetes. She did not smoke or drink alcohol.

Physical examination showed the following: height 153 $\mathrm{cm}$, weight $63.2 \mathrm{~kg}$ (body mass index $26.9 \mathrm{~kg} / \mathrm{m}^{2}$ ), blood pressure $112 / 68 \mathrm{mmHg}$, and pulse rate $68 / \mathrm{min}$. There was no abnormality in the head, face, neck, chest, abdomen or neurological system. Laboratory data on admission are shown in Table 1. Urinalysis, hematology, liver function, renal function, and electrolytes were within a normal range. Overnight fasting plasma glucose (FPG) was $71 \mathrm{mg} / \mathrm{dl}(70-109 \mathrm{mg} / \mathrm{dl})$, immunoreactive insulin (IRI) was $58.5 \mu \mathrm{U} / \mathrm{ml}(2.3-15.1 \mu \mathrm{U} / \mathrm{ml})$ and $\mathrm{C}$ peptide was $5.0 \mathrm{ng} / \mathrm{ml}(0.7-2.2 \mathrm{ng} / \mathrm{ml})$. The ratio of IRI/ FPG (Fajans index; normal range, below 0.3) was 0.82. On several occasions, her plasma glucose concentration ranged from 40 to $60 \mathrm{mg} / \mathrm{dl}$ and was accompanied by symptoms, which resolved with administration of oral carbohydrate. Anti-insulin antibodies were negative. An oral glucose tolerance test (OGTT) showed a diabetic pattern and hyperinsulinemia (Table 2A). A glucagon tolerance test showed hyperinsulinemia (Table 2C). Abdominal ultrasound revealed an approximately $15-\mathrm{mm}$ oval low echoic mass in the body of the pancreas (Fig. 1A). A computed tomography (CT) scan of the abdomen showed a hypervasucular tumor in the body of the pancreas (Fig. 1B). Magnetic resonance imaging of the abdomen demonstrated a pancreatic tumor. Selective celiac angiography showed an enhanced pancreatic tumor feeding from the splenic artery, and no evidence of hypervascular metastasis (Fig. 2). We diagnosed insulinoma by the pancreas feeding from the splenic artery and referred the patient for surgical assessment and treatment.

Table 2.

(A) 75-g oral glucose tolerance test before operation.

\begin{tabular}{lcccc}
\hline Time $(\mathrm{min})$ & 0 & 30 & 60 & 120 \\
Plasma glucose $(\mathrm{mg} / \mathrm{dl})$ & 75 & 159 & 202 & 220 \\
$\mathrm{IRI}(\mu \mathrm{U} / \mathrm{ml})$ & 40.0 & 44.7 & 45.4 & 82.6 \\
\hline
\end{tabular}

(B) 75-g oral glucose tolerance test after operation.

\begin{tabular}{lcccc}
\hline Time (min) & 0 & 30 & 60 & 120 \\
Plasma glucose (mg/dl) & 92 & 147 & 189 & 142 \\
IRI ( $\mu \mathrm{U} / \mathrm{ml})$ & 6.2 & 24.5 & 34.3 & 28.6 \\
\hline & & & & \\
(C) Glucagon tolerance test. & & & \\
\hline Time (min) & 0 & 6 \\
Plasma glucose (mg/dl) & 73 & 80 \\
C-peptide (ng/ml) & 3.1 & 8.6 \\
\hline
\end{tabular}

$\mathrm{IRI}$ : immunoreactive insulin

Table 1. Laboratory data on admission.

\begin{tabular}{|c|c|c|c|c|c|}
\hline \multicolumn{2}{|l|}{ Urinalysis } & \multicolumn{4}{|l|}{ Chemistry } \\
\hline Protein & $(-)$ & GOT & $30 \mathrm{IU} / \mathrm{I}$ & Fasting plasma glucose & $85 \mathrm{mg} / \mathrm{dl}$ \\
\hline Glucose & $(-)$ & GPT & $41 \mathrm{IU} / \mathrm{I}$ & & \\
\hline Blood & $(-)$ & $\mathrm{LDH}$ & $209 \mathrm{IU} / \mathrm{I}$ & Fasting immumoreactive insulin & $58.5 \mu \mathrm{U} / \mathrm{ml}(2.3-15.1)$ \\
\hline Acetone & $(-)$ & ALP & $276 \mathrm{IU} / \mathrm{I}$ & & \\
\hline $\mathrm{RBC}$ & $<1$ (hpf) & $\gamma$-GTP & $59 \mathrm{IU} / \mathrm{I}$ & Fasting plasma C peptide & $5.0 \mathrm{ng} / \mathrm{ml}(0.7-2.2)$ \\
\hline WBC & $<1$ (hpf) & T-Bil & $0.3 \mathrm{mg} / \mathrm{dl}$ & & \\
\hline \multirow[t]{2}{*}{ Cast } & $(-)$ & Total protein & $7.6 \mathrm{~g} / \mathrm{dl}$ & $\mathrm{Hb}_{\mathrm{A} 1 \mathrm{c}}$ & $4.0 \%$ \\
\hline & & Albumin & $4.5 \mathrm{~g} / \mathrm{dl}$ & & \\
\hline Hematology & & BUN & 17 mg/dl & Fasting free fatty acid & $0.16 \mathrm{mEq} / \mathrm{l}$ \\
\hline $\mathrm{RBC}$ & $440 \times 10^{4} / \mu l$ & Creatinine & $0.9 \mathrm{mg} / \mathrm{dl}$ & & \\
\hline $\mathrm{Hb}$ & $13.4 \mathrm{~g} / \mathrm{dl}$ & $\mathrm{Na}$ & $144 \mathrm{mEq} / \mathrm{l}$ & Gastrin & $79 \mathrm{pg} / \mathrm{ml}(37-172)$ \\
\hline $\mathrm{Ht}$ & $39.5 \%$ & $\mathrm{~K}$ & $4.1 \mathrm{mEq} / \mathrm{l}$ & & \\
\hline Platelet & $24.4 \times 10^{4} / \mathrm{mm}^{3}$ & $\mathrm{Cl}$ & $107 \mathrm{mEq} / \mathrm{l}$ & Glucagon & 139 pg/ml (23-197) \\
\hline WBC & $8,920 / \mu l$ & Amylase & 104 IU/I & & \\
\hline Basophil & $0.3 \%$ & & & & \\
\hline Eosinophil & $0.9 \%$ & Total cholesterol & $200 \mathrm{mg} / \mathrm{dl}$ & Apo-A I & 153 mg/dl \\
\hline Seg & $61.6 \%$ & HDL-cholesterol & 57 mg/dl & Apo-A II & $30.7 \mathrm{mg} / \mathrm{dl}$ \\
\hline Lymph & $33.4 \%$ & LDL-cholesterol & $116 \mathrm{mg} / \mathrm{dl}$ & Apo-B & 78 mg/dl \\
\hline \multirow[t]{3}{*}{ Monocyte } & $3.8 \%$ & Triglyceride & 70 mg/dl & Apo-C II & $3.5 \mathrm{mg} / \mathrm{dl}$ \\
\hline & & & & Apo-C III & $8.5 \mathrm{mg} / \mathrm{dl}$ \\
\hline & & CRP & $0.0 \mathrm{mg} / \mathrm{dl}$ & Apo-E & $3.0 \mathrm{mg} / \mathrm{dl}$ \\
\hline
\end{tabular}


After removal of the pancreatic body, tail and spleen, she no longer suffered from spontaneous hypoglycemia, and fasting plasma insulin decreased before and 3 months after the operation ( $58.5 \mathrm{vs} 5.7 \mu \mathrm{U} / \mathrm{ml})$. The resected specimen showed a solitary islet cell tumor of $16 \times 14 \times 14 \mathrm{~mm}$ in size. HE staining was performed ( $x$ 80) (Fig. 3A). Aldehyde-fuchsin staining was positive for pancreatic B-cell granules ( $\times 160)$ (Fig. 3B) (8). These results were compatible with insulinoma.

Before and 3 months after the operation, we examined the visceral fat and the glucose and lipid metabolism. Evaluation of the area of visceral fat was done by CT. The CT scan was performed at the umbilical level with the subject resting in the supine position. The visceral fat area was traced manually along the inside of the abdominal wall, and the number of pixels showing CT values between -50 and -150 Hounsfield units was calcu-

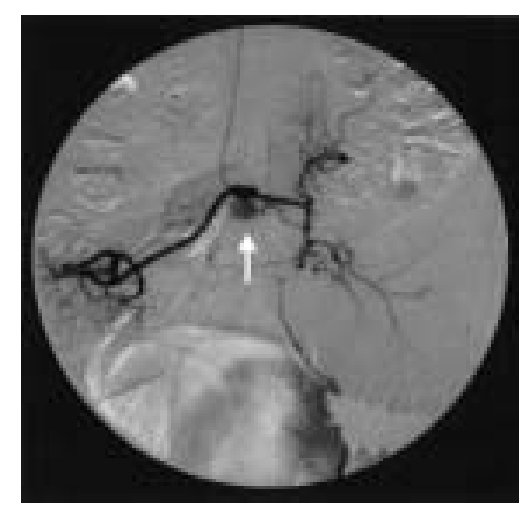

Fig. 2. Selective celiac angiography (digital subtraction angiography) showed an enhanced islet cell tumor feeding from the splenic artery, and no evidence of hypervascular metastasis.
(A)

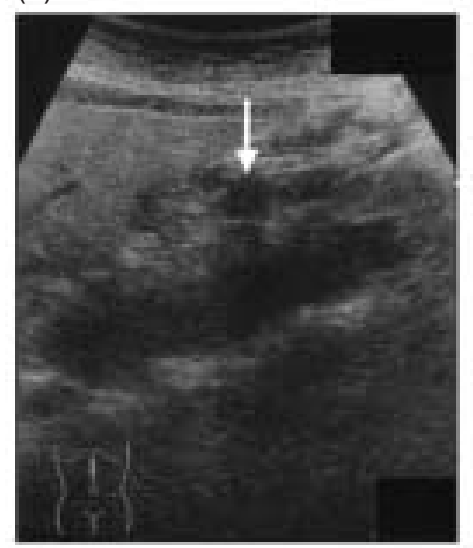

(B)

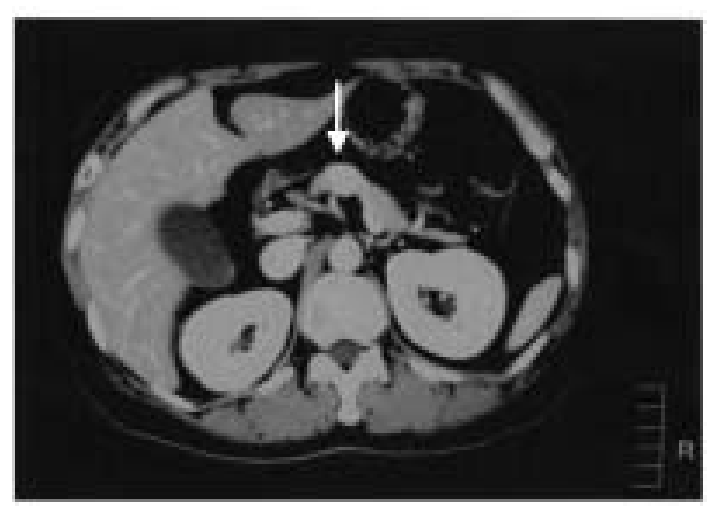

Fig. 1. Abdominal ultrasound and computed tomography (CT) scan of the abdomen before the operation. Abdominal ultrasound revealed an approximately $15-\mathrm{mm}$ oval low echoic mass in the body of the pancreas (A). A CT scan of the abdomen showed a hypervascular tumor in the body of the pancreas (B).

(A)

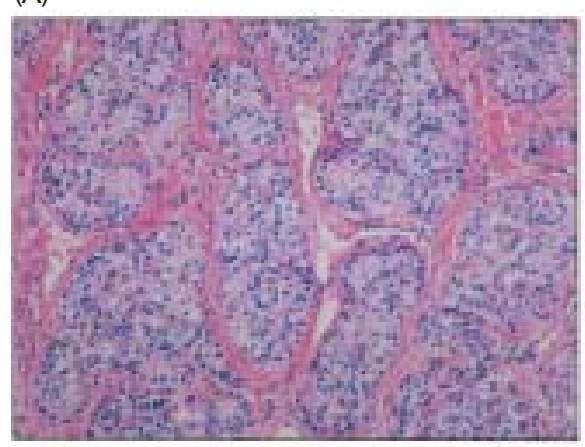

(B)

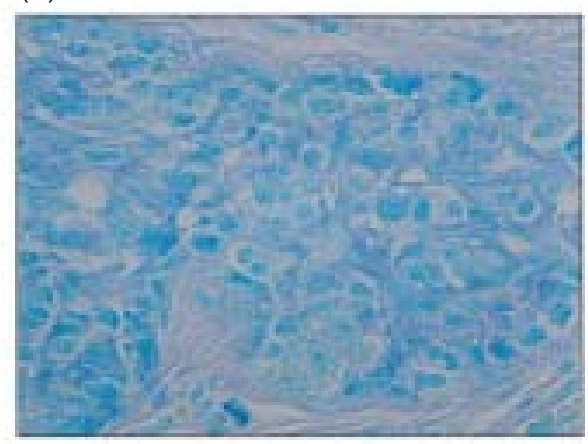

Fig. 3. The resected specimen showed a solitary islet cell. HE staining was performed $(x$ 80) (A). Aldehyde-fuchsin staining was positive for pancreatic B-cell granules ( $\times 160)(B)$. 
(A)

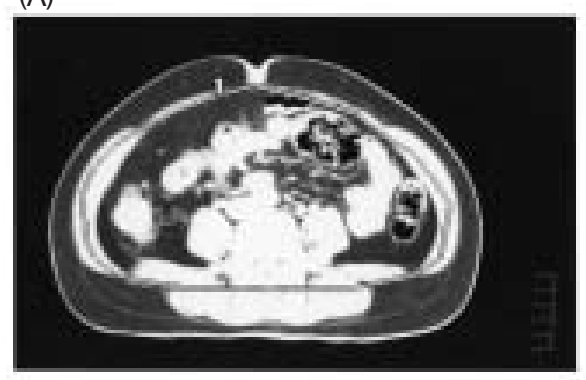

(B)

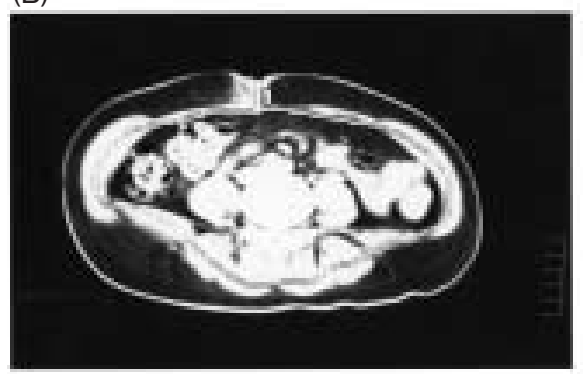

Fig. 4. The change in visceral fat and subcutaneous fat distribution was evaluated. Before the operation (visceral fat area $=132.6 \mathrm{~cm}^{2}$, subcutaneous fat area $\left.=152.3 \mathrm{~cm}^{2}\right)(\mathrm{A}) .3$ months after the operation (visceral fat area $=64.2 \mathrm{~cm}^{2}$, subcutaneous fat area $=141.6$ $\left.\mathrm{cm}^{2}\right)(\mathrm{B})$.

lated for this region. The subcutaneous fat area was calculated as follows: total fat area - visceral fat area. The change in visceral and subcutaneous fat distribution was studied. The changes in the glucose and lipid metabolism were measured in the following: $\mathrm{FPG}, \mathrm{HbA}_{1 \mathrm{c}}$, total cholesterol (TC), triglyceride (TG), high-density lipoprotein cholesterol (HDL-C), polyacrylamide gel disc electrophoresis of lipoproteins (PAG disc) (9), preheparin lipoprotein lipase (LPL) mass (10) (Table 3) and OGTT (Table 2B). LPL mass was measured by sandwich enzyme-linked immunosorbent assay using specific monoclonal antibody against bovine milk LPL, as described by Kobayashi et al. (11). For the assay, a kit from Daiichi Pure Chemicals (Tokyo, Japan) was used.

Removal of the insulinoma resulted in a decrease in the accumulation of visceral fat area, from 132.6 (Fig. 4A) to $64.2 \mathrm{~cm}^{2}$ (Fig. 4B). The subcutaneous fat area scarcely changed. Tumor necrosis factor- $\alpha$ (TNF- $\alpha$ ), which is secreted from adipose tissue and considered a cause of insulin resistance (12), was also decreased, although it remained within the normal limits $(6.0 \mathrm{vs} 3.7 \mathrm{pg} / \mathrm{ml})$ (Table 3).

Evaluation of the glucose and lipid metabolism was performed. Removal of the insulinoma resulted in a decrease in TC and TG and an increase in HDL-C. Preheparin LPL mass was especially increased. The midband on PAG disc, which appeared before the operation, was eliminated completely (Fig. 5). The OGTT result after the operation was improved to a non-diabetic pattern (Table 2B).

Blood pressure was unchanged after the operation.

\section{Discussion}

This case showed accumulation of visceral fat and insulin resistance under a diagnosis of insulinoma. Removal of this tumor was considered to improve the visceral adi-
Table 3. The changes in the glucose and lipid metabolism before and after the operation.

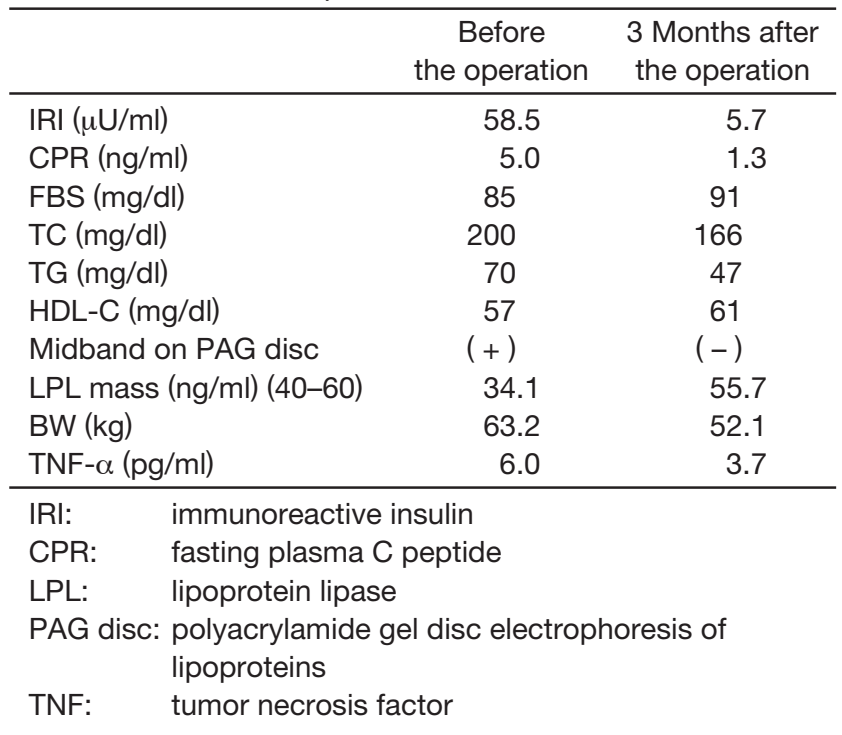

(A)

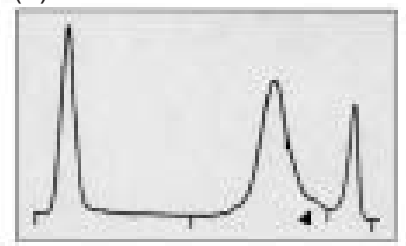

(B)

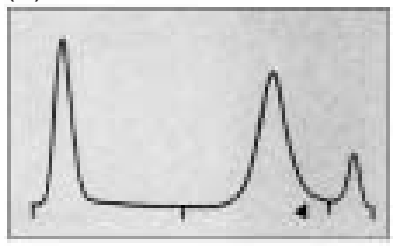

Fig. 5. The change in polyacrylamide gel disc electrophoresis of lipoproteins. Before the operation the midband appeared (arrowhead) (A). After the operation, it was eliminated completely (B). 
posity and insulin resistance. There are some reports that insulinoma brings insulin resistance, but the mechanism is unclear. It has been scarcely reported that insulinoma increases the amount of visceral fat. Yoshida et al. reported that insulinoma patients showed visceral adiposity and that insulin is the most important factor in visceral fat formation (13). We also considered that a feature of this case was that removal of the insulinoma reduced visceral fat selectively.

Adipose tissue is a key component of the endocrine system. It is metabolically very active and expresses various secretory proteins termed adipocytokines, including adiponectin, angiotensinogen/angiotensin 2 , TNF- $\alpha$, interleukin- 6 and plasminogen activator inhibitor type 1 (14-16). For example, TNF- $\alpha$ induced insulin resistance by a variety of mechanisms and is particularly secreted from visceral fat $(17,18)$. In this case, removal of the insulinoma reduced visceral fat selectively, and TNF- $\alpha$. There was no malignancy or inflammation. We considered that the TNF- $\alpha$ increased according to the accumulation of visceral fat. There have been no reports that insulinoma secretes TNF- $\alpha$, but we should examine the possibility by immunohistochemistry test for TNF- $\alpha$.

Before the operation, the midband on PAG disc was observed in the normolipidemic state. Apolipoproteins were within normal limits (Table 1). Totsuka et al. reported that the midband appeared in diabetes mellitus patients who were normolipidemic (19). The midband in this case might represent insulin resistance. We should have measured the apolipoprotein $E$ phenotype, but we did not.

After removal of the insulinoma, the LPL mass increased from $34.1 \mathrm{ng} / \mathrm{ml}$ to $55.7 \mathrm{ng} / \mathrm{ml}$. Tornvall et al. reported that LPL mass existed in preheparin serum, even though lipase activity was scarcely detached (10). They also reported a positive correlation between preheparin LPL mass and HDL-C and a weakly negative correlation with triglyceride. We reported that preheparin LPL mass could reflect some of the LPL production in a whole body, and might be related to insulin sensitivity $(20,21)$. Therefore, this patient was considered to have had insulin resistance. Wu et al. reported that TNF- $\alpha$ decreased LPL activity in rats (22). Suppression of LPL mass in this case might have depended on the direct action of TNF- $\alpha$.

The OGTT before the operation showed not only hyperinsulinemia but also a diabetic pattern. Generally, OGTT for insulinoma shows a hypoglycemic or normoglycemic pattern. Chang $\mathrm{HY}$ et al. reported that half of ten patients with insulinoma developed hypoglycemia during the OGTT (23). In this case, anti-insulin antibodies were negative. Therefore, a hyperglycemic pattern in this case might indicate insulin resistance. Improvement of the OGTT after the operation also supported the possibility that insulin resistance existed.

Generally, it is considered that the cause of metabolic syndrome is insulin resistance accompanied by hyperinsulinemia. It has also been reported that an increase in free fatty acid (FFA) causes visceral adiposity and reduction of muscle glucose uptake $(24,25)$. However, in our case, lipogenesis was caused by hyperinsulinemia accompanied by low FFA.

These results suggest that hyperinsulinemia is one of the factors that enhanced visceral adiposity and insulin resistance. This case report may indicate caution against high-glucose diet or an overdose injection of insulin or unsuitable sulfonylureas, which induce hyperinsulinemia, because hyperinsulinemia causes insulin resistance.

\section{Reference}

(1) Tokunaga K, Nakamura T, Kubo M, and Matsuzawa Y: Visceral fat syndrome. Nippon Naika Gakkai Zasshi, 81: 1831-1835, 1992 (in Japanese)

( 2 ) Kaplan NM: The deadly quartet. Upper-body obesity, glucose intolerance, hypertriglyceridemia, and hypertension. Arch Interm Med, 149: 1514-1520, 1989

( 3 ) Reaven GM: Pathophysiology of insulin resistance in human disease. Physiol Rev, 75: 473-486, 1995

(4) Grundy SM: Hypertriglyceridemia, insulin resistance, and the metabolic syndrome. Am J Cardiol, 83: 25F-29F, 1999

( 5 ) Meigs JB: Invited comm.entary: Insulin resistance syndrome? Syndrome $X$ ? Multiple metabolic syndrome? A syndrome at all? Factor analysis reveals patterns in the fabric of correlated metabolic risk factors. Am J Epidemiol, 152: 908-911, 2000

(6) Leonetti F, lozzo P, Giaccari A, Sbraccia P, Buongiorno A, Tamburrano G, and Andreani D: Absence of clinically overt atherosclerotic vascular disease and adverse changes in cardiovascular risk factors in 70 patients with insulinoma. J Endocrinol Invest, 16: 875-880, 1993

( 7 ) Nankervis A, Proietto J, Aitken P, and Alford F: Hyperinsulinaemia and insulin insensitivity: studies in subjects with insulinoma. Diabetologia, 28: 427431, 1985

( 8 ) Cole LJ and Nettleton GS: A histochemical investigation of the mechanism of aldehyde Fuchsin staining of pancreatic B-cell granules. Histochem J, 20: 635-41, 1988

(9) Kawano M, Shinomiya M, Kanzaki T, Morisaki N, Shirai K, Saito Y, and Yoshida S: An atherogenic midband lipoprotein: a risk factor for coronary artery disease in diabetes mellitus with hyperlipidemia. Diabetes Res Clin Pract, 41: 45-48, 1998

(10) Tornvall P, Olivercrona G, Karpe F, Andres H, and Olivercrona T: Lipoprotein lipase mass and activity in plasma and there increase after heparin are separate parameters with different relations to plasma lipoproteins. Arterioscler Thromb Vasc Biol, 15, 
1086-1093, 1995

(11) Kobayashi J, Hashimoto H, Fukamachi I, Tashiro J, Shirai K, Saito Y, and Yoshida S: Lipoprotein lipase mass and activity in severe hypertriglyceridemia. Clin Chim Acta 175, 158-163, 1993

(12) Hotamisligil GS, Shargill NS, and Spiegelman BM: Adipose expression of tumor necrosis factor-alpha: direct role in obesity-linked insulin resistance. Science, 259: 87-91, 1993

(13) Yoshida S, Inadera H, Ishikawa $Y$, Shinomiya M, Shirai K, and Saito Y: International Journal of Obesity, 15: 37-40, 1991

(14) Maeda K, Okubo K, Shimomura I, Mizuno K, Matsuzawa $Y$, and Matsubara K: Analysis of an expression profile of genes in the huma adipose tissue. Gene, 190: 227-235, 1997

(15) Spiegelman BM, Choy L, Hotamisligil GS, Graves $\mathrm{RA}$, and Tontonoz P: Regulation of adipocyte gene expression in differentiation and syndromes of obesity/diabetes. J Biol Chem, 268: 6823-6826, 1993

(16) Zhang Y, Proenca R, Maffei M, Barone M, Leoplold $\mathrm{L}$, and Friedman JM: Positional cloning of the mouse obese gene and its human homologue. Nature, 372: 425-432, 1994

(17) Hotamisligil GS: The role of TNF alpha and TNF receptors in obesity and insulin resistance. $J$ Intern Med, 245: 621-625, 1999

(18) Ross R: The pathogenesis of atherosclerosis: a perspective for the 1990s. Nature, 362: 801-809, 1993
(19) Totsuka M, Miyashita Y, Ito Y, Hashiguchi S, Urano $\mathrm{Y}$, Watanabe J, Tomioka H, and Shirai K: Protein of Fast $\beta$ Lipoprotein on the PAG Disc Electrophoresis and its Rple in Diabetic Complications. J Jpn Diabetes Soc, 40: 503-511, 1997

(20) Totsuka M, Miyashita Y, Ito Y, Watanabe H, Murano $\mathrm{T}$, and Shirai K: Enhancement of preheparin serum lipoprotein lipase mass by bezafibrate administration. Atherosclerosis, 153: 175-179, 2000

(21) Shirai K, Ito $Y$, Sasaki H, Totsuka M, Murano T, Watanabe $\mathrm{H}$, and Miyashita $\mathrm{Y}$ : The effect of insulin sensitizer, troglitazone, on lipoprotein lipase mass in preheparin serum. Diabetes Res Clin Prac, 46: 35-41, 1999

(22) Wu G, Brouckaert P, and Olivecrona T: Rapid downregulation of adipose tissue lipoprotein lipase activity on food deprivation. Evidence that TNF-alpha is involved. Am J Physiol Endocrinol Metab, 10: 257, 2003

(23) Chang HY, Huang HS, Lin JD, Huang BY, Huang $\mathrm{MJ}$, and Jeng LB: Insulinoma-clinical experiencee in ten cases. Changgeng Yi Xue Za Zhi, 17: 28-38, 1994

(24) Randle PJ, Garland PB, Hales CN, and Newsholme EA: The glucose fatty-acid cycle: Its role in insulin sensitivity and the metabolic disturbances of diabetes mellitus. Lancet, 1: 785, 1963

(25) Bjorntorp P: Metabolic abnormalities in visceral obesity. Ann Med, 24: 3-5, 1992 